\title{
Watershed Scale Response to Climate Change-Black Earth Creek Basin, Wisconsin
}

\section{Introduction}

General Circulation Model (GCM) simulations of future climate through 2099 project a wide range of possible scenarios (Intergovernmental Panel on Climate Change, 2007). To determine the sensitivity and potential effect of long-term climate change on the freshwater resources of the United States, the U.S. Geological Survey Global Change study, "An integrated watershed scale response to global change in selected basins across the United States" was started in 2008. The long- term goal of this national study is to provide the foundation for hydrologically based climate-change studies across the nation.

Fourteen basins for which the Precipitation Runoff Modeling System (PRMS) has been calibrated and evaluated were selected as study sites. PRMS is a deterministic, distributedparameter watershed model developed to evaluate the effects of various combinations of precipitation, temperature, and land use on streamflow and general basin hydrology. Output from five GCMs and four emission scenarios were used to develop an ensemble of climate-change scenarios for each basin. These ensembles were simulated with the corresponding PRMS model. This fact sheet summarizes the hydrologic effect and sensitivity of the PRMS simulations to climate change for the Black Earth Creek Basin in Wisconsin (U.S. Geological Survey streamflow-gaging station 05406500; fig. 1), presented in the project summary report (Markstrom and others, 2012) and a journal article (Hay and others, 2011).

\section{Study Area}

The Black Earth Creek Basin is a 118-square kilometer $\left(\mathrm{km}^{2}\right)$ basin in northwest Dane County, Wisconsin, that encompasses both glaciated and unglaciated settings. The creek is a high-quality trout stream located near an urbanizing fringe associated with the state capital, Madison. Because the land has been converted from agricultural to residential and commercial use, long-term evaluations of the effect of urbanization on the base flow and storm flow is needed. Urbanization may increase both storm flow (Steuer and Hunt, 2001) and non-point source loads of nutrients, pesticides, and sediments. Increased surface runoff captures water that normally would normally recharge to the groundwater system (Hunt and Steuer, 2001); consequently, urbanization can result in less groundwater being discharged as base flow to streams. Climate change can augment adverse effects of land use. Thus, an understanding of the surface water and groundwater systems can help evaluate the range of expected effects and aid in the assessment of the potential effectiveness of water management alternatives used to mitigate the effects of urbanization under current (water years 1989-1999) and future climate change. This information is critical for long-term management of water resources and health of the trout stream. A larger extent of the Black Earth Creek Basin was simulated with a fully coupled groundwater/surface-water model [GSFLOW(Markstrom and others, 2008)]. The work described in this fact sheet focuses on the PRMS portion of the GSFLOW application.

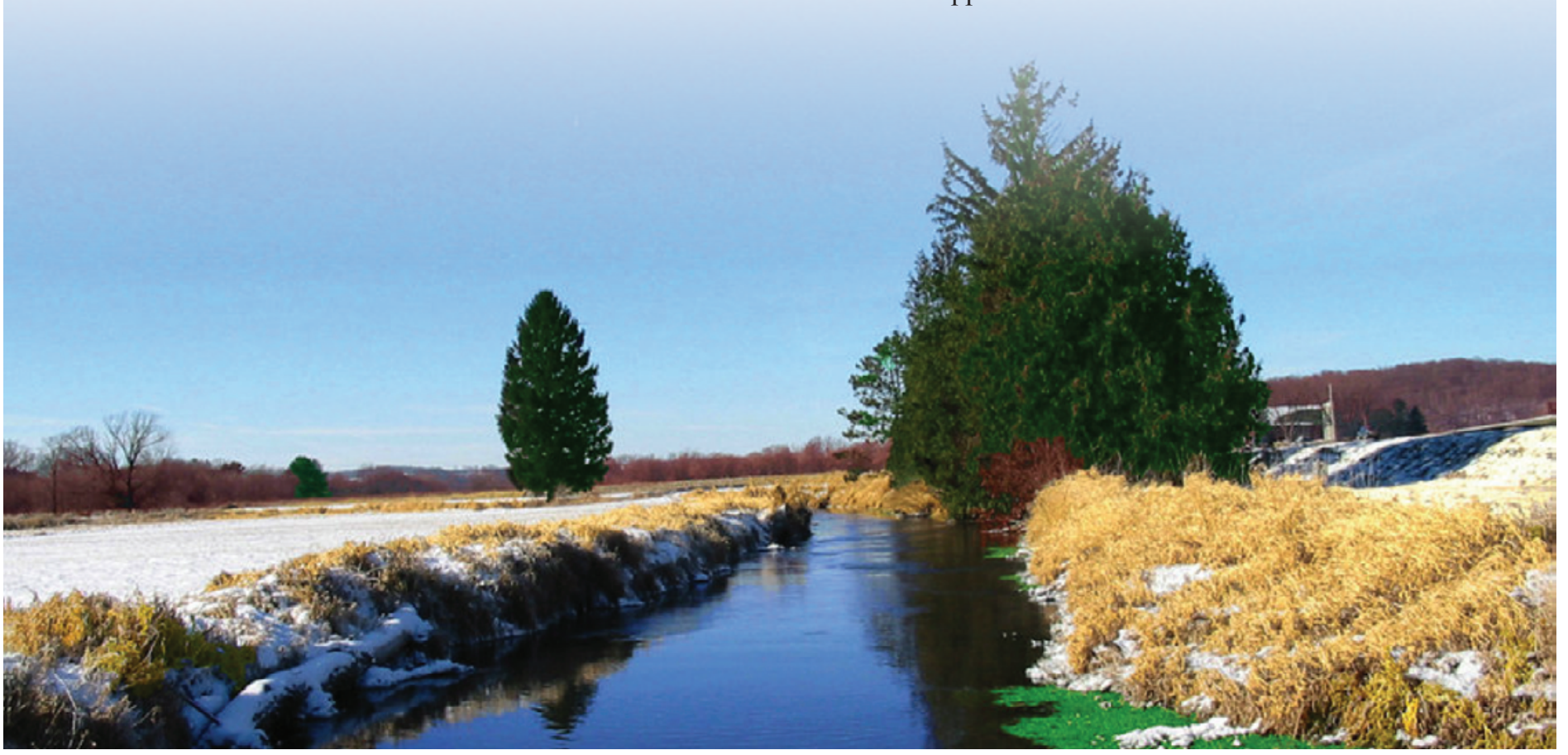




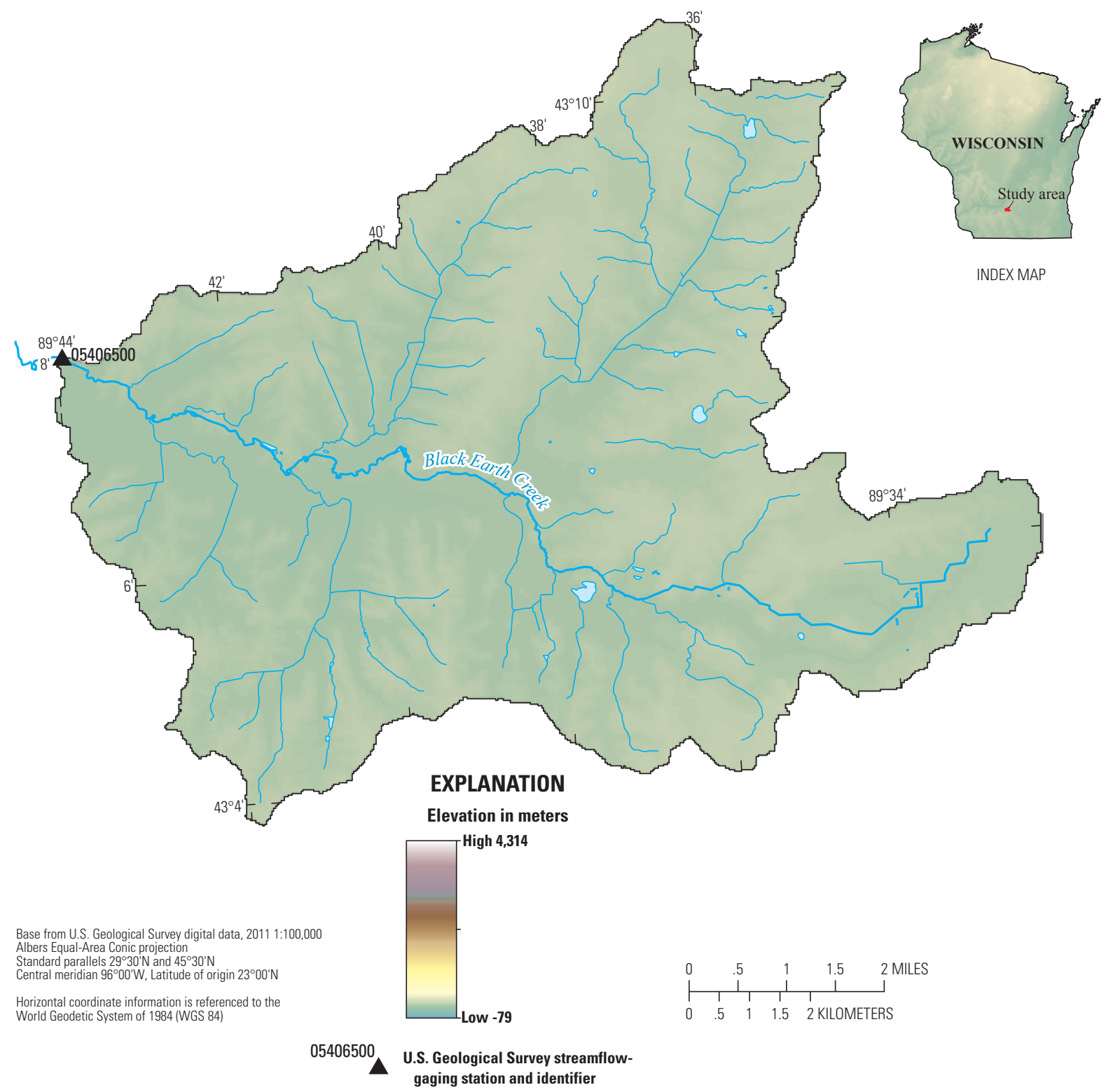

Figure 1. Precipitation Runoff Modeling System study locations, Black Earth Creek Basin, Wisconsin, and location of U.S. Geological Survey streamflow-gaging station 05406500 with a drainage area of 118 square kilometers and elevation range from 718 to 1,551 meters.

\section{General Circulation Models}

Given the uncertainty in climate modeling, it is desirable to use more than one GCM to obtain a range of potential future climatic conditions. Monthly precipitation and temperature output from five GCMs were processed (table 1).

Table 1. General Circulation Model (GCM) projections used in this study.

\begin{tabular}{ll}
\hline \multicolumn{1}{c}{ GCM } & \multicolumn{1}{c}{ Center and country of origin } \\
\hline BCC-BCM2.0 & Bjerknes Centre for Climate Research, Norway \\
CSIRO-Mk3.0 & Australia's Commonwealth Scientific and Industrial Research Organization, Australia \\
CSIRO-Mk3.5 & Australia's Commonwealth Scientific and Industrial Research Organization, Australia \\
INM-CM3.0 & Institute for Numerical Mathematics, Russia \\
MIROC3.2 & National Institute for Environmental Studies, Japan \\
\hline
\end{tabular}


The GCM outputs were obtained from the World Climate Research Programme's Coupled Model Intercomparison Project phase 3 multi-model dataset archive, which was referenced in the Intergovernmental Panel on Climate Change Fourth Assessment Special Report on Emission scenarios (Intergovernmental Panel on Climate Change, 2007). For each GCM, one current (water years 1988-1999) and three future emission scenarios were used and are described in table 2.

Table 2. Climate-change emission scenarios simulated by the General Circulation Models in this study.

\begin{tabular}{ll}
\hline \multicolumn{1}{c}{ Emission scenario } & \multicolumn{1}{c}{ Description/assumptions } \\
\hline 20C3M & $\begin{array}{l}\text { 20th century climate used to determine baseline (1989-1999) conditions } \\
\text { Rapid economic growth, a global population that peaks in mid-21st century and rapid introduction of new and } \\
\text { m1B }\end{array}$ \\
m1 & $\begin{array}{c}\text { Convergent world, with the same global population as Emission scenario A1B, but with more rapid changes in } \\
\text { economic structures toward a service and information economy that is more ecologically friendly } \\
\text { A2 }\end{array}$ \\
\hline
\end{tabular}

Climate-change fields were derived by calculating the change in climate from current (water years 1988-1999) to future conditions simulated by each GCM. The 20C3M simulation for water years 1988-1999 was used to represent current climatic conditions. This 12-year period of record was chosen based on the overlap of the available historical records from the 14 basins included in the national study. Climate change fields (percentage changes in precipitation and degree changes in temperature) were computed for 12 -year moving window periods (from 2001-2099) using the 20C3M (1988-1999) and the $\mathrm{A} 1 \mathrm{~B}, \mathrm{~B} 1$, and $\mathrm{A} 2$ emission scenarios. A 12-year moving window, starting in 2001 and ending in 2099, results in 1,320 future scenarios $[(88,12$-year climatologies, 1 per year starting with 2001-2012 and ending with 2088-2099) x (3 emission scenarios) $\mathrm{x}$ (5 GCMs)].

Climate-change scenarios were generated for PRMS by modifying PRMS precipitation and temperature inputs with the mean monthly climate change fields derived from the GCMs, resulting in 1,320 PRMS-input files. Table 3 shows the change (slope) and adjusted $\mathrm{R}^{2}(\operatorname{adj} \mathrm{R} 2)$ for the least squares fit to the trend line for selected output variables from the PRMS projections. The slope indicates the change in the selected variable by year. The adjusted $\mathrm{R}^{2}$ value gives an indication of the variability in the central tendency of the trend line.

Figure 2 shows a summary of the projected range in 11-year moving mean daily values of maximum temperature (fig. $2 A$ ), minimum temperature (fig. $2 B$ ), and precipitation (fig. $2 C$ ) by emission scenario. The first year of each 12-year simulation was used as PRMS initialization and is not included in the results. The three solid-colored lines indicate the 11-year moving mean values (x-axis indicates center of 11-year window) for the three future emission scenarios (central tendency of the five GCMs for each emission scenario). The projected range shown for each emission scenario indicates the range of potential future climatic conditions simulated by the five GCMs. All GCM simulations project steady increases in maximum and minimum temperature (table 3), with uncertainties associated with these GCM projections increasing with time. Both maximum and minimum temperatures show the smallest projected changes for the B1 emission scenario. Changes in precipitation are not as consistent as the projections of temperature, and show both increases and decreases in projected precipitation both between GCM simulations, and within the uncertainty envelope for a given emission scenario. The wide range and lack of significant trend in the precipitation projections indicate a large amount of uncertainty in the emission scenarios used in this study (table 3).

\section{Results}

Figure 3 shows the projected range in 11-year moving mean daily values of evapotranspiration (fig. $3 A$ ) and streamflow (fig. $3 B$ ) by emission scenario. The central tendency of the five GCMs for each of the three emission scenarios (indicated by the solid-colored lines) shows an increase in actual water lost from the basin because of evapotranspiration for the A1B and A2 emission scenarios (table 3). A negative trend in the annual streamflow is apparent for the A1B and A2 emission scenarios (table 3 ) resulting predominately from the projected increase in evapotranspiration.

Changes in the basin also can be characterized on a monthly basis (fig. 4). The red lines in figure 4 show PRMSsimulated mean monthly current conditions (1989-1999). The box plots represent the range in the mean monthly outputs for the five GCMs and three scenarios for 2030 (green, 2025-2035), 2060 (tan, 2055-2065) and 2090 (blue, 20852095). Results indicate a decrease in the snowpack (fig. $4 A$ ) and snow-covered (fig. $4 B$ ) area during the winter and early spring season (December-March), with an attendant reduction in the importance of the spring snowmelt (fig. $4 C$ ) to the stream, and a smaller increase of snowmelt during the winter months (November through March). Thus, the characterization of upper-midwestern streams as being spring snowmeltdominated may not hold if these emission scenarios of climate change are representative of future conditions. Rather, the hydrology would closer resemble more southerly United States streams. 

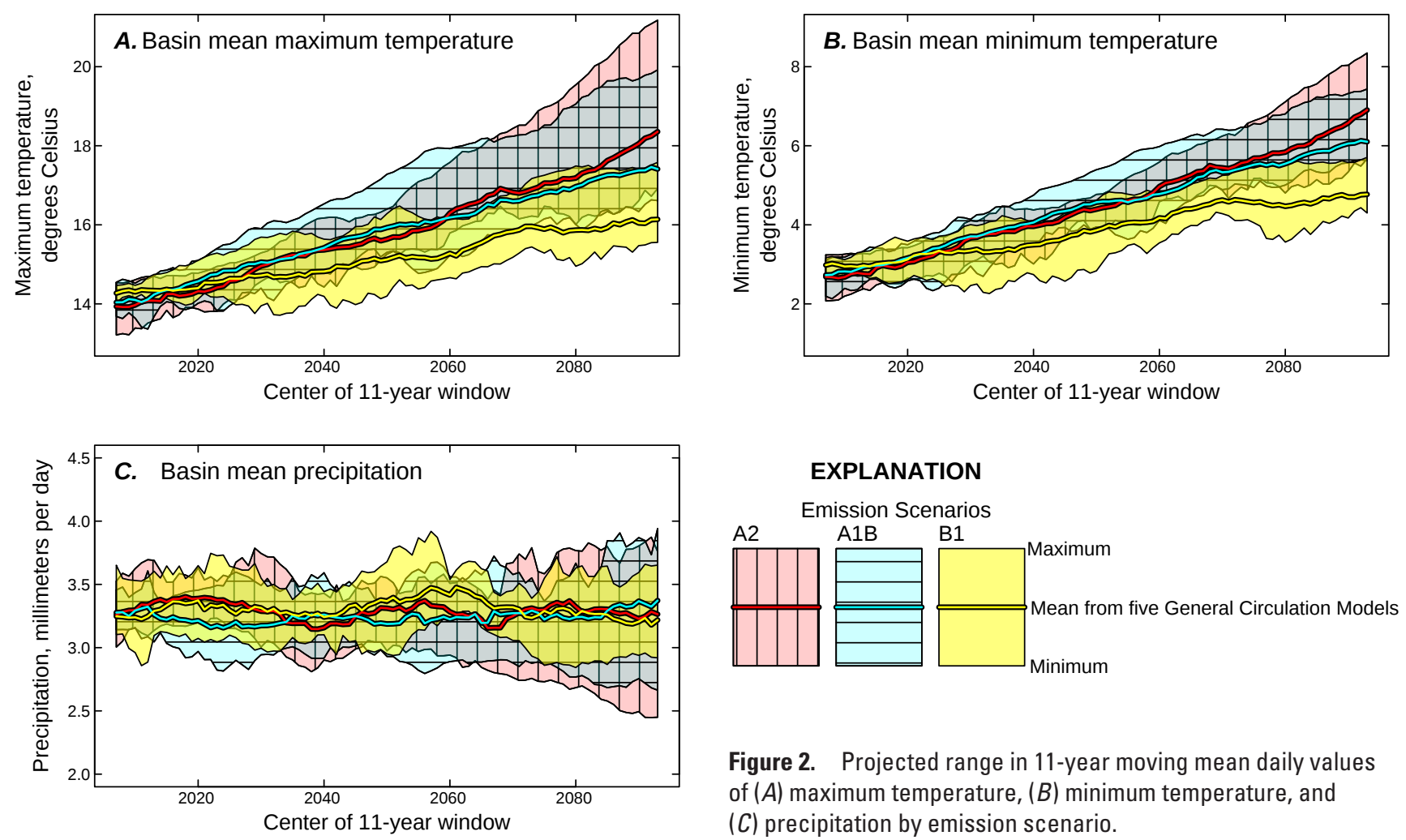

Figure 2. Projected range in 11-year moving mean daily values of $(A)$ maximum temperature, $(B)$ minimum temperature, and (C) precipitation by emission scenario.

Table 3. Projected change by year (slope) and adjusted $R^{2}$ (adjR2) based on the central tendencies of the five General Circulation Models for the three carbon emission scenarios for selected Precipitation Runoff Modeling System (PRMS) output variables.

[Blue indicates a significant negative trend and yellow indicates a significant positive trend $(\mathrm{p}<0.05)$ accounting for lag- 1 autocorrelation]

\begin{tabular}{|c|c|c|c|c|c|c|}
\hline \multirow{2}{*}{ PRMS output variable } & \multicolumn{2}{|c|}{$\begin{array}{c}\text { Emission scenario } \\
\text { A1B }\end{array}$} & \multicolumn{2}{|c|}{$\begin{array}{c}\text { Emission scenario } \\
\text { A2 }\end{array}$} & \multicolumn{2}{|c|}{$\begin{array}{c}\text { Emission scenario } \\
\text { B1 }\end{array}$} \\
\hline & slope & adjR2 & slope & adjR2 & slope & $\operatorname{adjR2}$ \\
\hline Maximum temperature in degrees Celsius & 0.040 & 1.00 & 0.049 & 0.99 & 0.024 & 0.97 \\
\hline Minimum temperature in degrees Celsius & 0.040 & 1.00 & 0.048 & 0.99 & 0.024 & 0.97 \\
\hline Precipitation in millimeters per day & 0.0009 & 0.21 & -0.0007 & 0.06 & -0.0003 & 0.00 \\
\hline Evapotranspiration in millimeters per day & 0.0027 & 0.92 & 0.0029 & 0.93 & 0.0018 & 0.69 \\
\hline Streamflow in cubic meters per second & -0.0014 & 0.59 & -0.0028 & 0.75 & -0.0016 & 0.49 \\
\hline Snow-covered area in percent per day & -0.16 & 0.97 & -0.18 & 0.98 & -0.11 & 0.89 \\
\hline Snowpack water equivalent in millimeters per day & -0.19 & 0.86 & -0.23 & 0.90 & -0.16 & 0.73 \\
\hline Snowmelt in millimeters per day & -0.0030 & 0.89 & -0.0035 & 0.91 & -0.0021 & 0.70 \\
\hline Soil moisture in millimeters per day & -0.0549 & 0.93 & -0.0785 & 0.95 & -0.0326 & 0.66 \\
\hline
\end{tabular}

The soil zone within the watershed-important for agricultural yields - also is expected to be affected by changing climate. On an annual basis, the basin mean soil moisture is expected to decrease by the end of the 21 st century for all emission scenarios (fig. 5 and table 3 ). This reduction in soil moisture is projected for nearly every month of the year for all 2030, 2060, and 2090 periods; moreover, the decrease is largest during the growing season months (fig. 6). Reduced soil moisture causes drier conditions in the root zone. A drier root zone likely causes other human-responses such as increased irrigation groundwater withdrawals to maintain current levels of agricultural production. Such simulations are beyond the scope of the current work; simulating effects of increased irrigation requires a coupled groundwater surfacewater model rather than the surface-water model used in this fact sheet. 

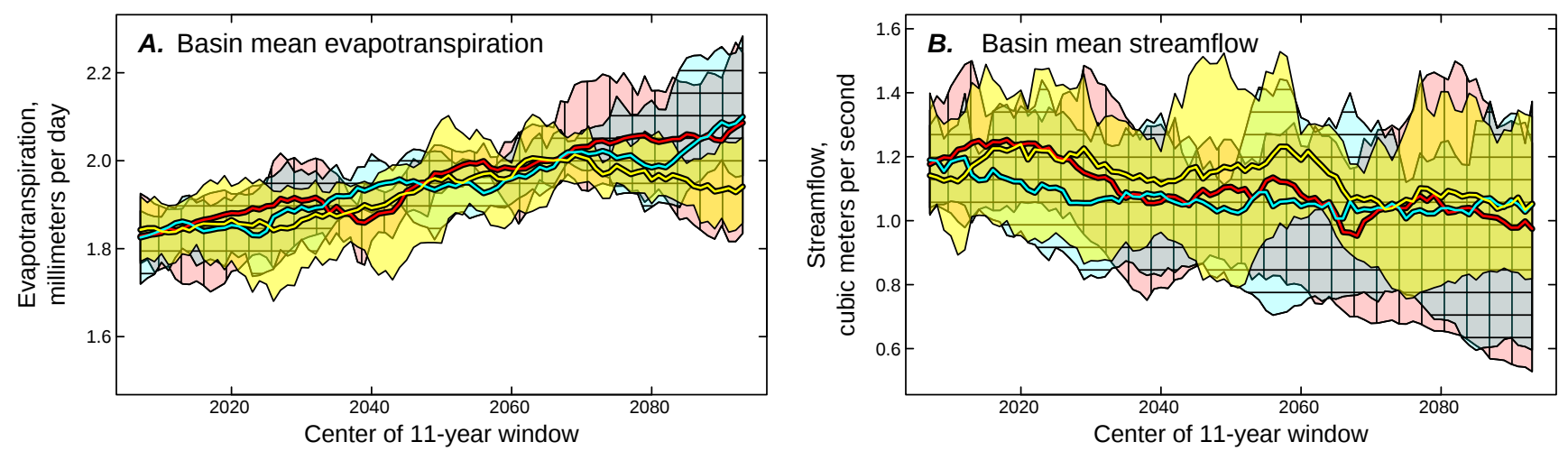

Figure 3. Projected range in 11-year moving mean daily values of $(A)$ evapotranspiration and $(B)$ streamflow by emission scenario.
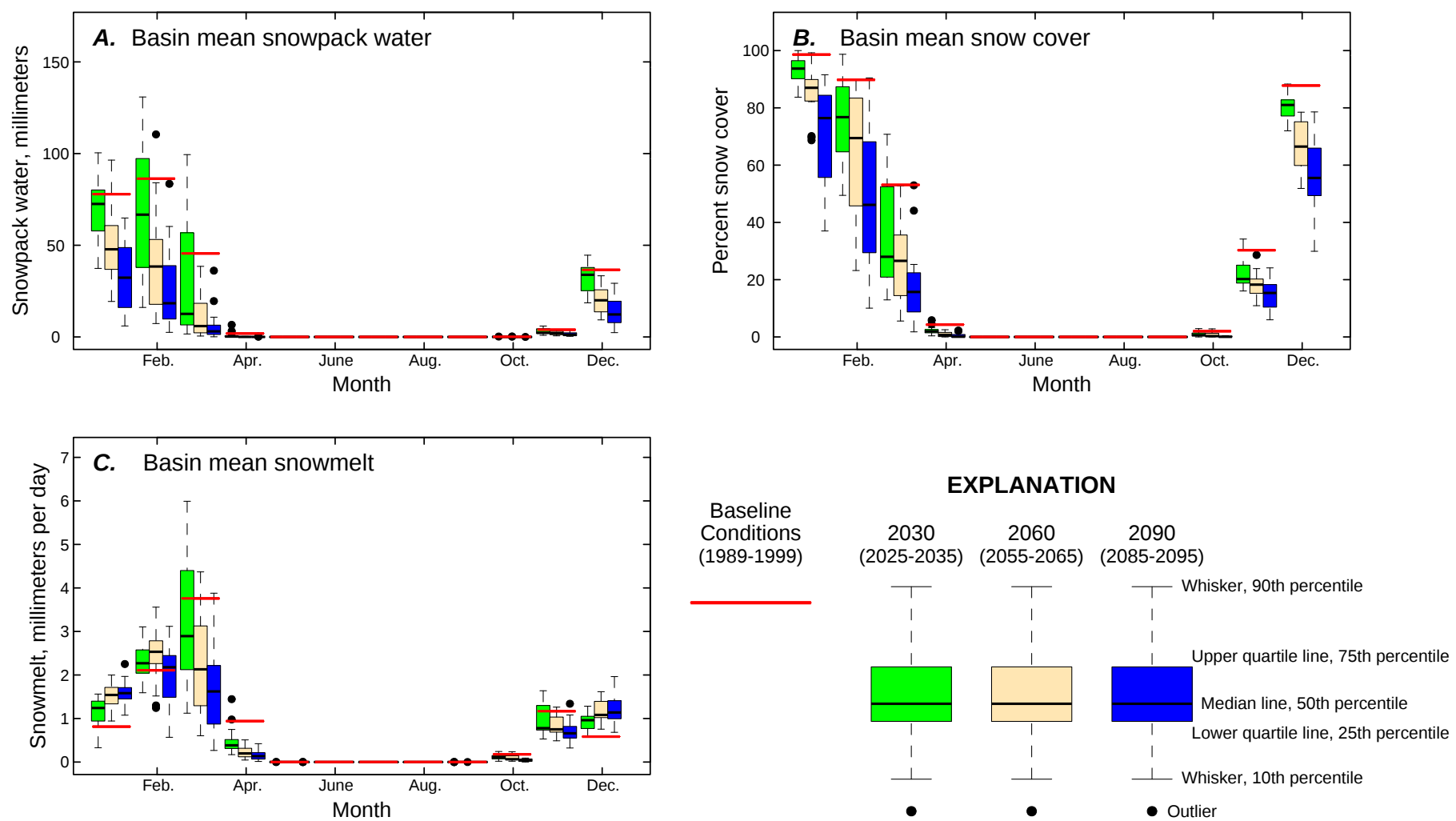

Figure 4. Mean daily $(A)$ snowpack water, $(B)$ snow-covered area, and $(C)$ snowmelt values by month for baseline conditions and projected range $(2030,2060$, and 2090) using the five General Circulation Models and three emission scenarios.

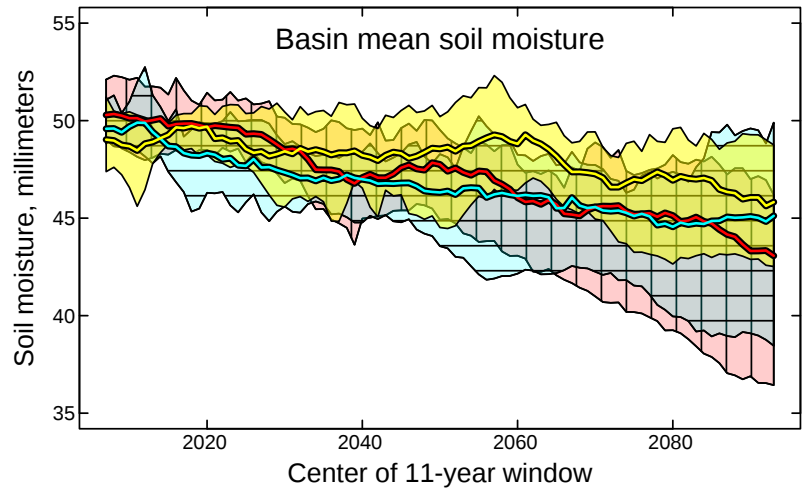

Figure 5. Projected range in 11-year moving mean daily values of soil moisture by emission scenario.

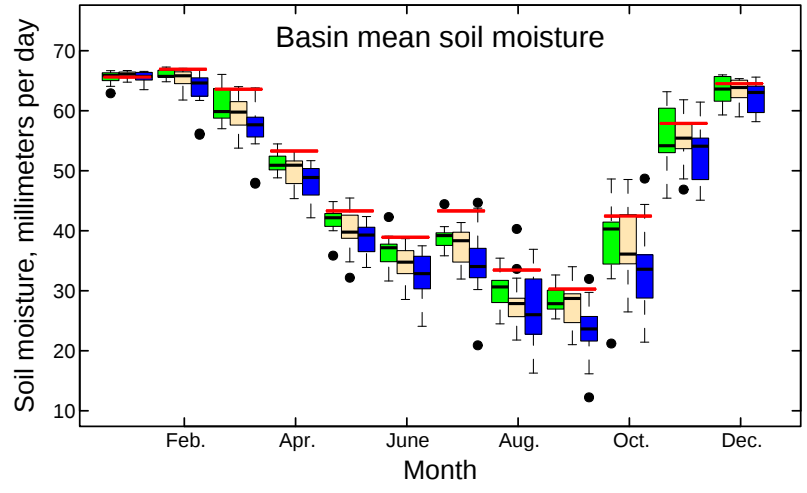

Figure 6. Mean daily soil moisture values by month for baseline conditions and projected range (2030, 2060, and 2090) using the five General Circulation Models and three emission scenarios. 


\section{Conclusion and Discussion}

In the Black Earth Creek Basin, the broader-scale effects of climate change on streamflow indicate an overall decrease in the importance of snowmelt and increase in the evapotranspiration out of the basin; however the uncertainty captured by the envelope of climate-change scenarios is large. Although mean streamflow averaged over a given year may not change appreciably, seasonal flow and local conditions such as soil moisture may change and, in turn, have effects on related stream-water quality and temperature. The results presented here did not consider potential future land-cover dynamics or potential increasing demand for water from the increased irrigation or urbanization in the basin. Thus, the inter-related effects of land use and climate change may exacerbate future adverse changes in the basin beyond what is shown in this work. However, these potentially adverse effects because of climate change and related changes to water use in the basin might be offset by land-use practices that change the flow of water in a beneficial way, such as rain gardens. The combined effects of climate change and urbanization in the Black Earth Creek Basin may alter both the quantity and timing of streamflow and have the potential to change the conditions of water quality that support biological diversity in aquatic communities. The scientific techniques described in the fact sheet can be augmented with other techniques in developing the science needed to address the combined effects of climate and land-cover dynamics on streamflow regimes.

\section{Selected References}

Hay, L.E., Markstrom, S.L., and Ward-Garrison, C.D., 2011, Watershed-scale response to climate change through the twenty-first century for selected basins across the United States, Earth Interactions, v. 15, 37 p.

Hunt, R.J., and Steuer, J.J., 2001, Evaluating the effects of urbanization and land-use planning using ground-water and surface-water models: U.S. Geological Survey Fact Sheet 102-01, 4 p.

Intergovernmental Panel on Climate Change, 2007, Summary for policymakers, in Climate change 2007-The physical science basis, Contributions of Working Group 1 to the Fourth Assessment Report of the Intergovernmental Panel on Climate Change: Cambridge and New York, Cambridge University Press, $18 \mathrm{p}$.

Markstrom, S.L., Hay, L.E., Ward-Garrison, C.D., Risley, J.C., Battaglin, W.A., Bjerklie, D.M., Chase, K.J., Christiansen, D.E., Dudley, R.W., Hunt, R.J., Koczot, K.M., Mastin, M.C., Regan, R.S., Viger, R.J., Vining, K.C., and Walker, J.F., 2012, An integrated watershed scale response to climate change for selected basins across the United States: U.S. Geological Survey Scientific Investigations Report 2011-5077, 142 p.

Steuer, J.J., and Hunt, R.J., 2001, Use of a watershed-modeling approach to assess hydrologic effects of urbanization, North Fork Pheasant Branch Basin near Middleton, Wisconsin: U.S. Geological Survey Water-Resources Investigations Report 01-4113, 49 p.

By Randall J. Hunt, John F. Walker, Steven M. Westenbroek, Lauren E. Hay, and Steven L. Markstrom

For more information visit the following Web sites:

http://wwwbrr.cr.usgs.gov/projects/SW_MoWS/

http://wi.water.usgs.gov/

http://www.usgs.gov/climate_landuse/ 